\title{
Review of HVDC Circuit Breakers Topologies.
}

\author{
J. K. Muriuki ${ }^{1}$, C. M. Muriithi ${ }^{2}$, L. $\mathrm{Ngoo}^{3}$, G. Nyakoe $^{4}$ \\ ${ }^{1}$ Dept. of Electrical \& Electronic Engineering, Jomo Kenyatta University of Agriculture and Technology, 62000, \\ Nairobi, 00200, Kenya \\ ${ }^{2}$ Dept. of Electrical \& Electronic Engineering, Technical University of Kenya, P.O. Box 52428-00200, Nairobi, \\ Kenya \\ ${ }^{3}$ Dept. of Electrical \& Electronic Engineering, Multimedia University, P.O. Box 15653-00503, Nairobi, Kenya. \\ ${ }^{4}$ Dept. of Electrical \& Electronic Engineering, Jomo Kenyatta University of Agriculture and Technology, 62000, \\ Nairobi, 00200, Kenya
}

\begin{abstract}
Voltage Source Converter-High Voltage Direct Current (VSC-HVDC) is the most efficient and reliable method for electrical power transmission over long distances. The greatest challenge with VSC-HVDC system is that short-circuit faults damages the converter valves and the transmission network. The fault clearing time for the available DC breakers are not fast enough and reliable to provide adequate protection for DC faults on multi-terminal networks. Hence, the development of fast DC breakers has been ongoing for some time and significant contributions have been made especially on the DC breaker response time and provisions to force artificial current to cross the zero current point. Though with these improvements, the research on fast DC breaker continue to attract a lot of interest. In addition, the integration of large amount of wind power to a conventional power grid demands a fast DC breaker. The need to integrate large amount of wind power has necessitated the development of VSC-HVDC system with multi-terminal systems. This ensures that under the influence of severe short-circuit faults, only the affected converters will be switched off while normal supplies to other converters remain uninterrupted. Currently, there are various types of DC breakers at the market while others are at various stages of development. This paper review and compares the available DC breakers topologies, recent developments made, challenges encountered and recommendations for DC breakers improvement.
\end{abstract}

Keywords DC Circuit Breaker Topologies, Multi-terminal system, Wind power, VSC-HVDC system.

\section{Introduction}

Globally, the demand for power has surpassed the supply imposing on many countries to diversify the search for other sources of energy especially from wind, solar, biogas, and hydropower. Wind energy has received more attention from researchers and the average capacity of installed and planned offshore/onshore wind farms is increasing daily. These wind farms are constructed in locations far away from the coast [1] because they have better wind characteristics essential for wind power generation. To efficiently and reliably transmit the power, a system based on Voltage Source Converter-High Voltage Direct Current (VSC-HVDC) is necessary. VSC-HVDC systems have the ability to independently control their active and reactive power in addition to power reversal capability an activity not easily achievable by Alternating Current (AC) system of transmission.

Notably, VSC-HVDC systems are highly vulnerable to short-circuit faults and can damage the converters and the transmission network. Many AC and DC breakers have been developed to provide protection to converters and the transmission systems. In [2], the frequency of failures from various sources is analyzed and the most outstanding are from short-circuit faults on the transmission lines, converter faults and the DC equipment faults amounting to $35.7 \%$. This is an indication that DC faults are prominent on VSC-HVDC system and its protection is a key factor to achieving stable and reliable power system. However, one major challenge for DC breakers is the inability to naturally create zero crossing point because of small reactance on the DC side. The current has to be artificially forced to cross the zero point to allow fault interruption. Under fault, the fault current is absorbed and dissipated quickly for fast fault elimination. Some of the methods adopted for absorption and dissipation of energy are the use of resistors, metal oxide varistors and surge arrestors. AC breakers fused for fault interruption are based on mechanical protection and experiences zero crossing point twice every cycle while HVDC breakers need a resonance circuit to artificially force the current to zero current crossing point. Another challenge for DC breaker is that under faults, the magnitudes of the fault current are much higher than its AC counterpart. This is normally associated with low DC reactance of the DC line thus, requiring a fast DC breaker to disconnect the fault before the fault current rise to uncontrollable levels. On the other hand, AC breakers have slower response time, hence not suitable for protection of the DC circuits. Recent 
developments in semiconductor technology have reduced the fault clearing time of a solid-state breaker to $5 \mathrm{~ms}$ [3]. This response time is long and DC circuit breakers, namely for high voltage applications are not commercially and widely available today [4]. This exposes the fast expanding DC power network to risk especially when subjected to short-circuit faults.

Globally, countries have interconnected power system. This ensures that power is taken where it is needed most so that member countries can benefit through pooling of large power generation stations and transmission systems, sharing of spinning reserves and use of the most economic energy resources available. These countries are far apart and the source of power generation is away from the load centers. This requires an efficient and reliable mode of power transmission based on VSC-HVDC system that incorporates multi-terminal system. In a multi-terminal system with large wind power integration, a fault on one converter can be cascaded to other converter stations; consequently a fast DC breaker is necessary to protect the VSC-HVDC system. To avert the damage it is important to use an HVDC circuit breaker that can quickly isolate the faulty section from the system [5]. VSC-HVDC system utilizes Insulated Gate Bipolar Transistors (IGBT) for fast switching purposes. These devices are known to have fast switching operation and have high efficiency that fast DC breakers possess. The modern HVDC system uses VSC which act as a constant current source and have capacitors to store energy with very little need for large filters and reactive power supply. Further, it has the ability to generate its own reactive power consequently controlling its active power and voltage effectively. VSC-HVDC system has the potential to change the direction of power flow by changing the direction of the current while for a CSC, the DC voltage polarity have to be altered a task not easily achievable. It is therefore important that the interconnected power system and VSC-HVDC transmission system incorporate a fast and reliable DC breaker to provide reliable and efficient protection against short-circuit faults.

The major challenge with DC circuit breakers is the process of fault interruption; a task not easily achieved. AC circuit breakers easily interrupt the fault because they have natural zero current crossing ability. Challenges affecting DC CB fault interruption response time can be found in [6]-[7]:

$>$ The rise of the fault current in DC grids is very high compared to AC grids because of the low impedance of the DC lines; this requires a fast DC breaker.

$>$ In AC grids the arc in the circuit breaker under current interruption is extinguished by the zero current crossing which is provided naturally by the system. In DC grids, the zero current crossing must be provided by the circuit breaker itself. One of the traditional methods is to provide resonant current to enable zero crossing point to be reached.

$>$ Unlike AC grids, the magnetic energy of DC grids is stored in the system inductance. The DC circuit breaker must dissipate this energy through mutual inductance or through a resistive element.

$>$ The DC breaker must withstand the residual overvoltage after the current interruption a condition different from AC breakers.

This paper compares the available DC breakers topologies that includes; electromechanical circuit breakers, hybrid circuit breakers, solid-state circuit breakers and the new solid-state circuit breaker. From the analysis and based on various technologies, recommendations for $\mathrm{CB}$ improvement in terms of response time and stability is presented for future research.

\subsection{VSC-HVDC Systems}

Globally, the integration of large amount of renewable energy resources such as offshore/onshore wind farms has attracted a lot of interest from various energy stakeholders. Most of the wind farms are constructed far away from the load centers, considerably at the offshore due to high wind density and space availability. Because of long distance of power transmission, considerable power cable for high voltage transmission to a receiving onshore grid [8] is necessary. Therefore, based on the long distances and plants capacity, transmitting power over conventional AC cables is not feasible because of high power losses [9]. Two HVDC technologies in use today are Current Source Converter-High Voltage Direct Current (CSC-HVDC) and VSC-HVDC [10]. The CSC-HVDC system do not have the ability to independently control its active and reactive power and need high pass filters to eliminate the harmonics on the AC side of the network. Also, they lack the ability for power reversal capability because the voltage polarity has to be changed which is difficult to achieve [10]-[11]. This necessitated the development of an efficient and reliable system based on VSC-HVDC system with multiterminal grid. VSC-HVDC system have proved to be the best option for future multi-terminal HVDC system for integration and bulk transmission of wind energy over long distances where termination to the AC grid is done. Some additional advantages of VSC-HVDC are:

$>$ Avoidance of commutation failures due to disturbances in the $\mathrm{AC}$ network.

$>$ Possibility to connect the VSC-HVDC system to a "weak" AC network or even to one where no generation source is available, and naturally, the short-circuit level is very low. 
$>$ No need of transformers to assist the commutation process of the converter's fully controlled semiconductors.

Though VSC-HVDC systems are the most suitable for power transmission, they also suffer setbacks such as the need for fast HVDC circuit breakers and high initial investment cost. The available DC breakers do not provide the fast response time necessary to protect the converters and the transmission system.

\subsection{HVDC Circuit Breakers Overview}

Fault interruptions in AC system are easily achievable because AC breakers have the ability to interrupt fault twice every cycle during the current zero crossing point, a feature deficient in DC breakers. In DC systems, fault interruption is difficult and requires special considerations because DC breakers do not have the ability to naturally drive the current to zero crossing point. The absence of current zero crossing point associated with small inductance on the DC side of the system causes the rate of rise of DC fault current to be considerably high therefore requiring a very fast interruption technology [12]. The only major challenge with AC breakers is the slow response in clearing the fault. This delay causes damage to transmission network and other power associated components thus necessitating a fast breaker based on DC technology. The DC current in DC breakers have no current zero crossing point thus making it difficult to interrupt the fault [11]. One of the traditional approaches for achieving current zero crossing point during the fault is the use of resonant current as shown in fig. 1. [13].

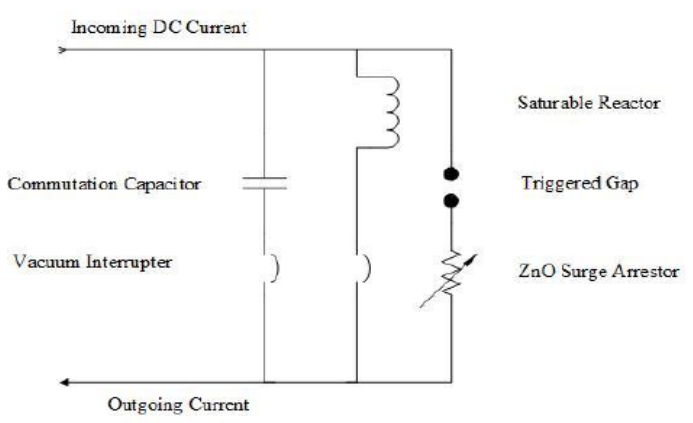

Fig1. DC circuit breaker with resonant feature

Under normal condition, the current flows through the vacuum interrupter (DC breaker) charging the commutation capacitor. However, when a fault occurs, the DC breaker gets a signal to trip the breaker. This results into opening of the DC breaker and discharging the stored energy into the inductor through the triggered gap. This operation creates a current zero crossing point. The energy absorbed by the inductor is dissipated to the surge arrestor and converted into heat. The surge arrestor is the absorbing agent for energy stored on the line while the resonant circuit creates the much needed current zero crossing point. The inductive reactance assists in maintaining the rate of current change at a controlled level and the high pass filter circuit regulates the recovery voltage while at the same time filtering the harmonics from entering the AC system [13].

Wind farms are located far from the load centers and the harnessed wind power has to be transferred over long distances and in large quantities. This makes VSC-HVDC systems, the only available feasible solution for long distance transmission due to its inherent ability to control active and reactive power independently. Short-circuit faults result to high fault current and if the DC breaker is not fast in isolation of the fault, it may damage the converters. To effectively limit the fault current under short-circuit faults in DC circuits, the traditional thyristors based on HVDC uses large inductor as DC filters [14]. However, VSC-HVDC system uses the insulated gate bipolar transistor (IGBT) to provide fast switching operation.

\section{Types Of HVDC Circuit Breakers Topologies}

This paper reviews four types of DC breakers topologies. These are the electromechanical circuit breakers, solid-state circuit breakers, hybrid circuit breakers and new design of solid state circuit breakers.

\section{Electromechanical Circuit Breakers}

Theelectromechanical resonance $\mathrm{CB}$ is classified into passive and active resonance. The passive resonance is an old technology initially developed for CSC-HVDC systems [15]. These mechanical breakers are heavy and bulky. They have long breaker response time and negligibly low power losses compared to all other DC breakers. Due to bulkiness and long breaker response time, the interest in the utilization of 
electromechanical breakers to provide protection on DC networks has dropped. Figure 2 shows an electromechanical HVDC passive resonance circuit breaker.

\section{a) Electromechanical passive resonance $\mathrm{CB}$}

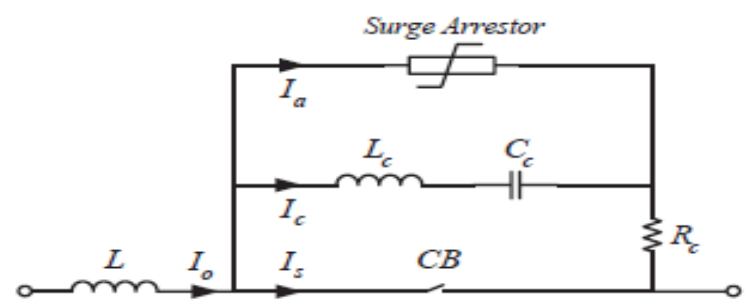

Fig2. Electromechanical HVDC passive resonance CB

The nominal current path is usually where the DC current $\left(I_{S}\right)$ passes through and the switch $(\mathrm{CB})$ is closed during the normal operation. The commutation path consists of a series resonant circuit with an inductor and a capacitor $\left(L_{c}\right.$ and $\left.C_{c}\right)$ that provide the condition suitable for creation of zero current point necessary for DC breaker fault interruption. The surge arrestor is an absorption element for energy generated during fault where interruption is required, to enable current oscillation to occur between the nominal and the commutation path at the natural frequency. Thus, zero current crossing occurs when the amplitude of the oscillating current is larger than that of the input current and the switch can now interrupt the current in the nominal path. Consequently, current (Io) will continue to flow and will charge the capacitor, however, if the capacitor voltage exceeds a given value, which is chosen to be the voltage capability of the DC breaker, the energy absorption path (surge arrestor) will act resulting to current decrease thereby providing an ideal zero point for current interruption. Electromechanical HVDC circuit breakers have been in use for many years and are available up to $500 \mathrm{kV}, 5 \mathrm{kA}$ with a fault-clearing time of between 60-100ms [16]. The development in semiconductor technology has made electromechanical breakers less attractive for protection of short-circuit faults particularly on VSC-HVDC multi-terminal systems.

To understand the interruption process it is necessary to analyze the current equation during the process. The differential equation during fault interruption can be written as below:

$L_{c} \frac{d^{2} i s}{d i^{2}}+\left(R_{C}+\frac{\partial_{u a r c}}{\partial_{i s}}\right) \frac{d_{i s}}{d t}+\frac{1}{C_{S}} i_{s}=\frac{I_{O}}{C_{C}}$

$i_{S}=I_{O}\left(1+e^{\frac{1}{2 L}\left(R_{C}+\frac{\partial u a r c}{d_{i s}}\right)} \cdot \operatorname{Sin} \omega_{c} t\right)$

Where, $\omega_{c}=\sqrt{ }\left(\frac{1}{L_{C .} C_{c}}\right)$.

If $R_{C}+\frac{\partial_{u a r c}}{d_{i s}}<0$; then $i_{s}$ will oscillate with increasing amplitude. The first zero crossing of current will be enough for the breaker to interrupt the fault being the ideal fault break off point for the DC breaker.

b) Electromechanical active resonance $\mathbf{C B}$

Figure3. Shows the electromechanical DC breaker based on active resonance and also known as two stage interruption methods [16].

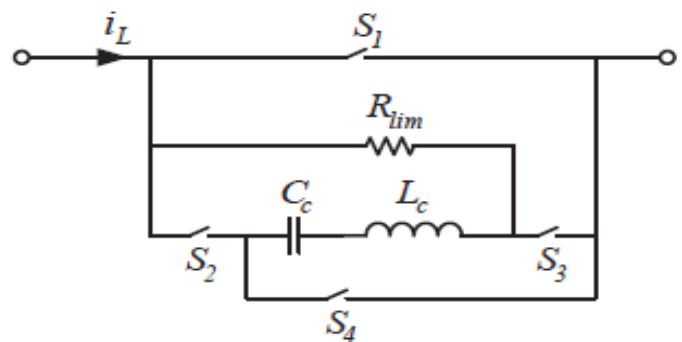

Fig 3. Active resonance circuit breaker

Under normal operation, current flows through the breaker $S_{1}$ while switches $S_{2}, S_{3}$ and $S_{4}$ are in open position. However, under fault condition, $S_{1}$ open while $S_{2}$ and $S_{3}$ close simultaneously. When the reverse current flowing through the $L_{c} C_{c}$ branch opposes the fault current and equals the amount of fault current, then, a zero crossing point is reached and fault interruption occurs. The current is then, commutated to the parallel 
branches. The difference between passive and active resonance is that passive CB uses surge arrestors while active resonance $\mathrm{CB}$ uses resistor to dissipate the heat generated during fault. Further, surge arrestors are not as rugged as resistors. When subjected to frequent short-circuit faults, they wear out rapidly and are not long lasting and reliable. They are also costly. The development in semiconductor technology has made surge arrestorsless attractive in energy absorption and dissipation under short-circuit faults.

\section{Solid State Circuit Breakers (SSCB)}

The SSCB's have fast response time, lighter, and easier to repair and fix compared to electromechanical DC breakers. SSCB is an active area of research and new contributions are found in [17][18]. This type of CB has two topologies as discussed in [18]. These are where the CB is paralleling a surge arrestor and the other is a CB with a freewheeling diode.

The fig. 4 below shows a CB paralleling a surge arrestor.

a) $\mathrm{CB}$ employing surge arrestor

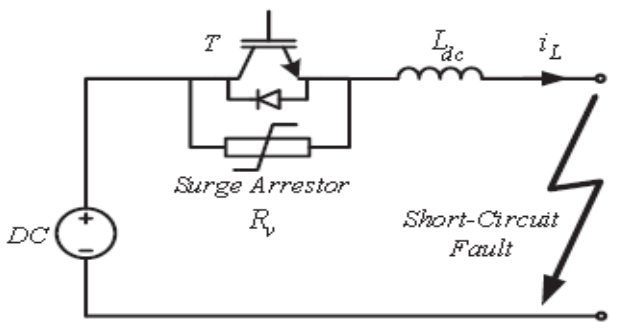

Fig4. CB paralleling a surge arrestor.

Under normal condition, current flows from the DC source to the load through the IGBT however, when a fault is detected, the semiconductor switches off. This causes rapid increase in voltage until the surge arrestor begins to conduct. Any voltage higher than the grid voltage is blocked due to the design of the surge arrestor. This in turn, leads to the demagnetization of the line inductance. Then the load current commutates to the surge arrestor. Also, the surge voltage across the IGBT (T) is limited to the clamping voltage of the surge arrestor. Clamping voltage of surge arrestor is assumed as $V_{d c}+V_{\text {margin }}$. It is also assumed that the impedance of the fault point is slightly small. When IGBT turns off at time $t=0$,

$V_{\text {margin }}$ is applied to $L_{d c}$, so the inductor current can be calculated as follows:

$i_{L}=I_{O}-\frac{V_{M a r g i n}}{L_{d c}} t$

Where $I_{O}$ is the amplitude of the fault current at $\quad t=0$. The time to turn off the fault current $T_{\text {open }}$ is derived as follows:

$$
T_{\text {open }}=\frac{L_{d c}}{V_{\text {margin }}} I_{o}
$$

The energy absorbed by the surge arrestor can be given by:

$W_{R}=\left(\frac{V_{d c}}{V_{\operatorname{margin}}}+1\right) \frac{1}{2} L_{d c} I^{2} o$

$W_{R}$ is the total energy to be absorbed by the surge arrestors and suppressed at the time of fault clearance , $L_{d c}$ is the inductance of the system and $I^{2} O$ is the short-circuit current. In high voltage applications, $V_{d c}$ is larger than $V_{\text {margin }}$ to enable suppression of the voltage across the IGBT and reduce its conduction loss. In such a case, the term in the parenthesis of equation 5 becomes large [4]. The energy dissipated is therefore given by $\frac{1}{2} L_{d c} I^{2} o$ and the more the energy in IGBT is suppressed, the more capacity the surge arrestor needs to accommodate [17].

The second topology employs CB with freewheeling diode to bypass any reverse voltage impulse thus protecting the IGBT against voltage spikes. It also uses the surge arrestor as an absorbing agent for the heat generated during the fault and dissipates it as quickly as possible. This quick absorption and dissipation of the heat generated improves the breaker response time and reliability an important element for CB. The arrangement with the diode reduces the energy absorbed by the CSSCB with suppressing the surge voltage across the IGBT. Equation 5 and 6 compares the energy absorbed by the two arrangement of CSSCB. The arrangement with the freewheeling diode absorbs less energy than the one with surge arrestor. This indicates that $\mathrm{CB}$ employing freewheeling diode is able to quickly absorb and dissipate the energy. 
$W_{R}=\frac{1}{2} L_{d c} I^{2} o$

A circuit configuration of the solid-state DC circuit breaker using a freewheeling diode is shown in Fig.5.

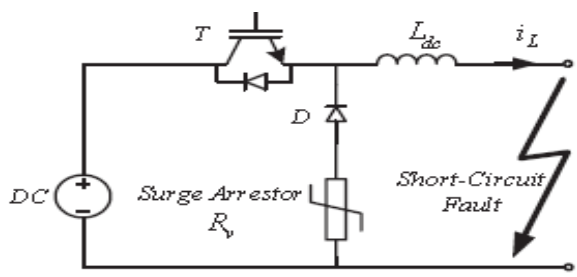

Fig5. Solid-State DC breaker with freewheeling diode.

\section{Hybrid DC breakers.}

Hybrid DC circuit breakers provide new opportunities for fast switching and quenching of the arc. As the name suggest, they employ mechanical switches and the solid-state devices for switching operation. The use of electronic components that are sensitive to short-circuit faults makes the hybrid CB expensive. However, failure by the breaker to timely isolate the fault can be detrimental to both human being and the components being protected thus, hybrid $\mathrm{CB}$ continues to attract a lot of attention as recently witnessed in [19]. Further, ABB and ALSTOM have developed Hybrid HVDC CB prototypes with some considerable improvements in recent research [11], [20]-[21]. There are many available topologies of hybrid CB at various stages of development, but only two attract more attention. Figure 6 shows topology 1 of the hybrid DC-CB

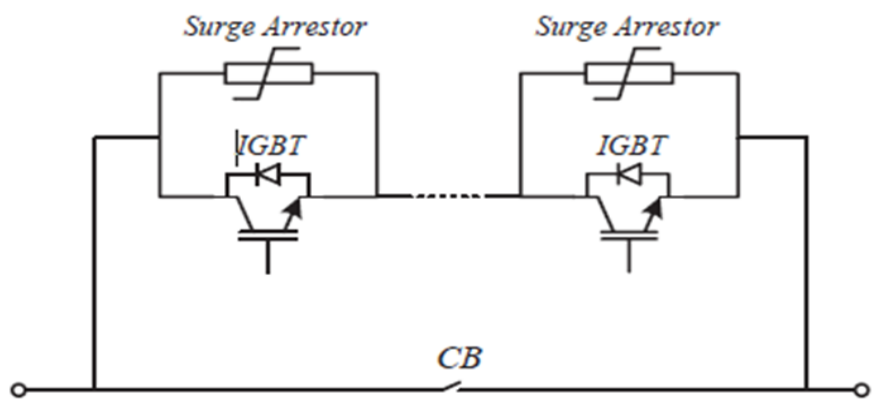

Fig 6. Topology 1 of Hybrid circuit breaker

The operation of topology 1 of hybrid CB is similar to that of SSCB only that the hybrid breaker has additional sets of solid-state switches connected in parallel. Compared to other breakers, hybrid CB has low losses and because of the solid state switches, it is a faster and reliable.Figure 7 shows the topology 2 of hybrid CB [22].

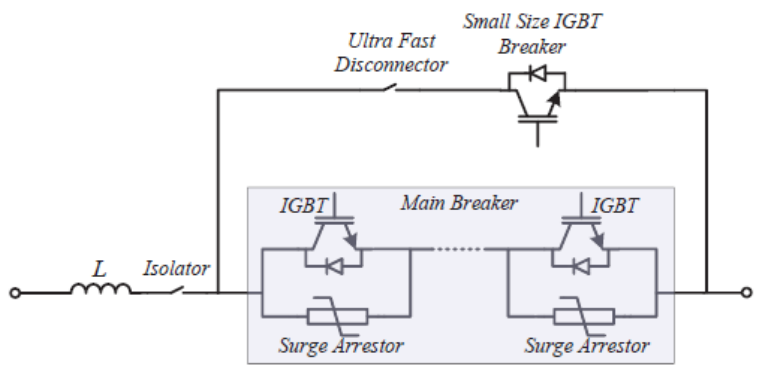

Fig 7. Topology 2 of Hybrid circuit breaker

Under normal operation current flows through the Ultra-Fast Disconnector (UFD) switch and the small size IGBT breaker while the current in the main breaker is zero. When a DC fault occurs, the small size IGBT breaker immediately commutates the current to the main DC Breaker analogous to solid-state CB and the UFD switch opens. UFD maintain low voltage loss while enabling fast switching operation. With the mechanical switch in open position, the main DC breaker breaks the current. The mechanical switch opens with zero current and low voltage stress. The fast disconnector will be exposed to the recovery voltage defined by the protective level of the arrester banks first after being in open position while the main DC breaker opens. Recent 
developments in semiconductor technology have reduced the fault interruption time. An example is ABB whose hybrid CB has a faults clearing time of within 5ms [22].

\section{The New Solid-State Circuit Breaker (NSSCB)}

Normally, DC breakers have challenges with fault interruption because of the inability to naturally allow current to cross the zero point similar to AC breakers. Many of these breakers rely on resonant circuit to create zero current crossing point and also use the surge arrestors/resistors/mutual inductance to absorb and dissipate the energy generated at the time of fault. The NSSCB utilizes the mutual inductance instead of surge arrestors to absorb the energy and dissipate it to the resistive element as heat. Also, a diode is included in the circuit to bypass any reverse voltage spikes thus protecting the IGBT. This is a relatively newer breaker that has the ability to clear the fault in $5 \mathrm{~ms}$ thus necessitating a design of a fast DC breaker that will avoid large $d i / d t$ current. The figure 8 below shows the NSSCB.

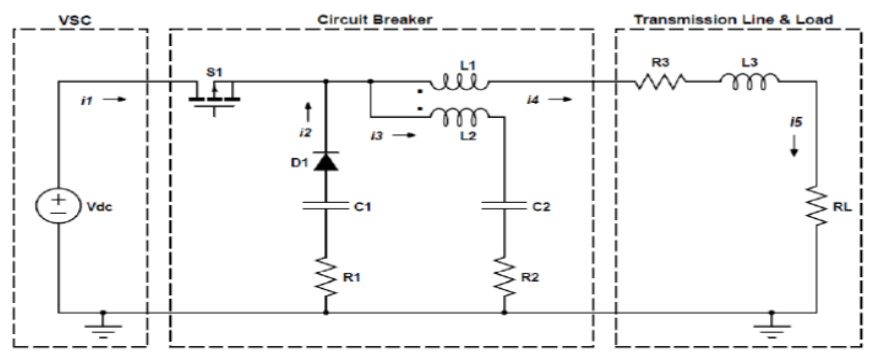

Fig 8. The New Solid-State DC Circuit Breaker

The use of mutual inductance eliminates the need for surge arrestors because any abnormal condition in either current or voltage can be suppressed and damped by the high pass filter $\left(R_{2}, C_{2}\right)$. Under normal operation, the current flowing through $R_{2}$ is insignificant and the resistor only operates under short-circuit fault to dissipate the energy absorbed by the mutual inductance.

\section{Comparison Of The DC Circuit Breakers Topologies}

The four types of DC breakers are summarized into five characteristics:

$>$ Interruption time

$>$ Power losses

$>$ voltage rating

$>$ Current rating.

$>$ Cost

The table below shows the relationships of the four types of the DC breakers [18].

Table 1: Comparison of DC breakers characteristics

\begin{tabular}{|c|c|c|c|c|c|}
\hline DC breaker type & $\begin{array}{l}\text { Interruption time } \\
\mathbf{m} / \mathbf{s}\end{array}$ & $\begin{array}{l}\text { \% of the VSC station } \\
\text { power losses. }\end{array}$ & $\begin{array}{l}\text { Voltage rating } \\
\text { kV }\end{array}$ & $\begin{array}{l}\text { Current rating } \\
\text { kA }\end{array}$ & Cost \\
\hline Electromechanical & 60 & 0.00 & 550 & 5 & $4,450,000$ \\
\hline Solid state & 40 & 30 & 800 & 5 & 300,000 \\
\hline Hybrid & $2-30$ & 0.1 & 320 & 9 & $54,544,000$ \\
\hline New solid state & 10 & 30 & 800 & 5 & $60,000,000$ \\
\hline
\end{tabular}

Table 1, shows that the new solid state DC breaker has many advantages compared to other types of DC breakers in terms of the cost, the high voltage transmission and current rating. The high voltage across the inductor allows overvoltage which is a good ingredient for fast demagnetization process thus limiting the peak current to low levels. These characteristics further limit the damage that can be exposed to converters valves under fault. Although this DC breaker seems to have many advantages, it has the highest percentage of the VSC station power losses and is vulnerable to reverse voltage spikes generated at the time of current disruption. This huge power loss occurs during the on-state conduction because the resistance of the new solid state DC breakers is negligibly small. Though the cost of the new solid state breakers seems prohibitive, in reality it is not so, because the fast switching of the IGBT provides excellent protection against the internal converter faults and short-circuit on the DC transmission network whose cost are relatively high.Further comparisons of the DC breakers based on various voltages are shown in [5]. 
Review of HVDC Circuit Breakers Topologies.

Table 2: Cost comparison for four different DC circuit breaker topologies

\begin{tabular}{|l|l|l|l|l|}
\hline Voltage in KV & Solid-state & Electromechanical & Hybrid DC breaker & Forced commutation \\
\hline 6 & 6000 & 5400 & 8,100 & 11,400 \\
\hline 12 & 9000 & 8800 & 27,500 & 21,200 \\
\hline 20 & 21000 & 18,000 & 47,500 & 34,800 \\
\hline 150 & 300,000 & $4,450,000$ & $54,544,000$ & $2,602,000$ \\
\hline
\end{tabular}

From table 1 and 2, we find that the solid-state CB are cheaper compared to other four types of DC breakers and have the ability for fast switching operation. Notable, the major disadvantage is high power losses. However, the power losses are minimized in high voltage applications while the costs are minimal. This makes solid-state breakers economical and continues to find applications in protection of VSC-HVDC multi-terminal systems.

\section{Conclusions And Recommendations}

In this paper, review of DC breakers topologies is analyzed. The major challenge with DC breakers is the inability to naturally create the zero current crossing point. However, the current in DC breaker is forcefully driven to zero crossing point by use of many methods; one such method is based on resonant current. This feature enables the DC breaker to reach current zero crossing point to interrupt the current, dissipate the energy stored from the system inductance and withstand the voltage response after current interruption. From the analysis, the new solid state circuit breaker (NSSCB) has superior characteristics compared to the other three configurations in terms of fault clearing time and high voltage applications. A novel control method for the NSSCB can be an interesting study to further enhance the breaker interruption time.

Solid state circuit breakers have disadvantage of slow breaker response time especially when thyristors are used for switching purposes however, the use of insulated gate bipolar transistors in SSCB reduces the fault clearing time of the breaker but with high power conversion losses. Further study on the use of thyrsitors and transistors in SSCB is important so that a compromise position can be found to enable fast switching solid-state breakers with minimal conversion power losses. Solid-state circuit breakers have difficulties in differentiating the transient faults from the permanent faults. The use of DC fault current limiters in HVDC system can be investigated.

Zinc oxide $(\mathrm{ZnO})$ has traditionally been used in surge arrestors for absorption and dissipation of energy during fault. During fault, the surge arrestors suppress and damp the high voltage transients thus protecting the VSC-HVDC system and other power associated components. It is therefore important to carry out further studies on developing a combination of mutual inductance and high pass filter as a replacement to surge arrestors in transmission industry. The high conversion power losses at low voltage in solid-state switches can be overcome by use of pure semiconductor switch with negligible on-state losses without compromising the breaker operation time. An example would be the study of the wide bandgap semiconductor devices such as Silicon Carbide $(\mathrm{SiC})$ or Gallium Nitride $(\mathrm{GaN})$ known to have very minimal power losses, larger breakdown field and higher saturation velocity ccompared to traditional silicon $(\mathrm{Si})$ semiconductor material. They find applications in power VSC-HVDC system so that high power efficiency, high operation temperature and high switching frequency can be achieved. This would be an interesting study. Hybrid circuit breaker uses electromechanical and solid-state CBs. The use of mechanical switch reduces the power losses while the solidstate switch reduces the breaker breaking time. This makes the hybrid breaker the most suitable for medium voltage applications with reasonable fault clearing time.

The development of a fast, efficient and reliable electromechanical HVDC breaker is a challenging undertaking. However, the use of semiconductor-based HVDC breakers can easily overcome the limitations of the operational speed and voltage, but they also generate large power losses in the range of $30 \%$ of the losses of a VSC station. Passive components are necessary for creation of the resonance circuit that drives the current to cross the zero point thus enabling the breaker to interrupt the fault fast and easily.

\section{References}

[1] "The European offshore wind industry - key trends and statistics 2013", Report by the European Wind Energy Association, Jan 2014

[2] M. G. Bennett, N. S. Dhaliwal and A. Leirbukt "A survey of the reliability of HVDC systems throughout the world during 200201', CIGRE, Paris, 2012.

[3] T. Eriksson, M. Backman, and S. Halen, "A low loss mechanical HVDC breaker for HVDC grid applications," in Cigre Session 2014, 2014.

[4] Franck, C.M., "HVDC Circuit Breakers: A Review Identifying Future Research Needs," Power Delivery, IEEE Transactions on, vol.26, no.2, pp.998, 1007, April 2011

[5] Meyer, C.; Kowal, M.; De Doncker, R.W., "Circuit breaker concepts for future high-power DC-applications, "Industry Applications Conference, 2005. Fourteenth IAS Annual Meeting. Conference Record of the 2005, vol.2, no., pp.860, 866 Vol. 2, 2-6 Oct. 2005 M. Callavik, A. Blomberg, J. Hafner, and B. Jacobson, "The hybrid HVDC breaker," ABB Grid Systems Tech. Paper, 2012.

[7] R. Adapa, "High-wire act: HVDC technology: The state of the art," Power and Energy Magazine, IEEE, vol. 10, no. 6, pp. 18-29, Nov 2012. 
[8] "The European offshore wind industry - key trends and statistics 2013", Report by the European Wind Energy Association, Jan 2014

[9] E. Koldby and M. Hyttinen, "Challenges on the road to an offshore HVDC grid," presented at the Nordic Wind Power Conf., Bornholm, Denmark, Sep. 10-11, 2009.

[10] Jovcic, D.; Van Hertem, D.; Linden, K.; Taisne, J.-P.; Grieshaber, W., "Feasibility of DC transmission networks," Innovative Smart Grid Technologies (ISGT Europe), 2011 2nd IEEE PES International Conference and Exhibition on, vol., no., pp.1,8, 5-7 Dec. 2011

[11] Callavik, M.; Bahrman, M.; Sandeberg, P., "Technology developments and plans to solve operational challenges facilitating the HVDC offshore grid," Power and Energy Society General Meeting, 2012 IEEE , vol., no., pp.1,6, 22-26 July 2012.

[12] E. Koldby and M. Hyttinen, "Challenges on the road to an offshore HVDC grid," presented at the Nordic Wind Power Conf., Bornholm, Denmark, September. 10-11, 2009.

[13] B.L. Damsky, P. Barkan, I. Imam, W. Premerlani, “A New HVDC Circuit Breaker Design System for + 400 kV," 7th IEE/PE Transmission and Distribution Conf. and Exp., CH1139-5/0000-0230500, 75, Apr. 1979

[14] Wasserrab A, Balzer G Calculation of short circuit currents in HVDC systems. In: Proceedings of the $46^{\text {th }}$ international universities' power engineering conference (UPEC'11), Soest, Germany, 5-8 Sep 2011, (2011)

[15] Pauli, B.; Mauthe, G.; Ruoss, E.; Ecklin, G.; Porter, J.;Vithayathil, J., "Development of a high current VDC circuit breaker with fast fault clearing capability," Power Delivery,IEEE Transactions on , vol.3, no.4, pp.2072,2080, Oct 1988

[16] Christian M. Franck, Member of IEEE. HVDC Circuit Breakers: A Review Identifying Future Research needs .IEEE 2011.

[17] Sano, K.; Takasaki, M., "A surge-less solid-state dc circuit breaker for voltage source converter based HVDC transmission systems," Energy Conversion Congress and Exposition (ECCE), 2012 IEEE , vol., no., pp.4426,4431, 15- 20 Sept. 2012

[18] Magnusson, J.; Saers, R.; Liljestrand, L.; Engdahl, G., "Separation of the Energy Absorption and Overvoltage Protection in SolidState Breakers by the Use of Parallel Varistors," Power Electronics, IEEE Transactions on , vol.29, no.6, pp.2715,2722, June 2014

[19] A. Shukla and G. Demetriades, “A survey on hybrid circuit-breaker topologies," Power Delivery, IEEE Transactions on, vol. 30, no. 2, pp. 627-641, Apr 2015.

[20] R. Adapa, "High-wire act: HVDC technology: The state of the art," Power and Energy Magazine, IEEE, vol. 10, no. 6, pp. 18-29, Nov 2012.

[21] C. Davidson, R. Whitehouse, C. Barker, J.P. Dupraz, and W. Grieshaber, "A new ultra-fast HVDC circuit breaker for meshed dc networks," in AC and DC Power Transmission, 11th IET International Conference on, Feb 2015, pp. 1-7.

[22] J. HAFNER, B. JACOBSON, "Proactive Hybrid HVDC Breakers - A key innovation for reliable HVDC grids, "presented at electric power system of the future - Integrating supergrids and microgrids International Symposium, Bologna, Italy, 13-15 Sep., 2011 